\title{
Epididymal Dirofilariasis in a Child: First Case Report from Bulgaria
}

\author{
Valeri Velev ${ }^{\mathrm{a}}$ Teofil Pelov ${ }^{\mathrm{b}}$ Tzvetomir Garev ${ }^{\mathrm{c}}$ Stoyan Peev ${ }^{\mathrm{b}}$ \\ Iskren Kaftandjiev ${ }^{d}$ Rumen Harizanov ${ }^{d}$
}

aDepartment of Infectious Diseases, Hospital for Infectious and Parasitic Diseases "Prof. Iv. Kirov," Medical University of Sofia, Sofia, Bulgaria; 'Department of Pediatric Urology, University Hospital for Emergency Medicine "Pirogov," Sofia, Bulgaria; 'Department of Pathology, University Hospital for Emergency Medicine "Pirogov," Sofia, Bulgaria; ${ }^{\mathrm{d}}$ Department of Parasitology and Tropical Medicine, National Centre for Infectious and Parasitic Diseases, Sofia, Bulgaria

\section{Significance of the Study}

- Human dirofilariasis is often misdiagnosed as a malignancy that requires invasive diagnostic procedures and surgery. Dirofilariasis of the male reproductive system is uncommon, with about 20 cases reported in Europe. Worldwide cases of infected children are rarely recorded. Here we describe an unusual case of dirofilariasis with involvement of the epididymis in an 11-year-old boy who completely recovered after surgical treatment.

\section{Keywords}

Dirofilaria repens $\cdot$ Infection · Epididymis

\begin{abstract}
Objective: To present case of a child with epididymal dirofilariasis. Clinical Presentation and Intervention: An 11-yearold boy was admitted to the Clinic of Pediatric Urology for elective surgery treatment of epididymal cyst on the left side. After removal, the cyst was sent for histological examination. Microscopic examination of the histological slides revealed cross-sections of a nematode belonging to Dirofilaria spp., differentiated morphologically as $D$. repens. After surgery, the patient recovered completely. Conclusions: In most parts around the world, dirofilariasis is a rare and neglected infection. Nevertheless, the clinicians and pathologists must be informed about it. @2018 The Author(s)

Published by S. Karger AG, Basel
\end{abstract}

\section{Introduction}

Human dirofilariasis is a zoonotic infection caused by filarial nematodes of the genus Dirofilaria, the most common causative species being $D$. repens and $D$. immitis. While $D$. immitis has a worldwide distribution, $D$. repens is currently found only in Europe, Asia, and Africa [1, 2]. Definitive hosts and reservoirs of the parasites are domesticated and wild dogs, rarely cats, and the most common vectors are insects of the family Culicidae, genera Anopheles, Aedes, and Culex [1]. Humans are accidently included into the epizootic chain as dead-end hosts, most commonly for D. repens, which often ends up as subcutaneous or ocular localization, but may also affect other tissues of the human body [3].

Bulgaria is among the countries where human dirofilariasis is a relatively rare disease. Only a few sporadic cases of human infection caused by $D$. repens have been re-

\begin{tabular}{ll}
\hline KARGER & $\begin{array}{l}\text { (c) } 2018 \text { The Author(s) } \\
\text { Published by S. Karger AG, Basel }\end{array}$ \\
E-Mail karger@karger.com & $\begin{array}{l}\text { This is an Open Access article licensed under the Creative Commons } \\
\text { Attribution-NonCommercial-4.0 International License (CC BY-NC) } \\
\text { (http://www.karger.com/Services/OpenAccessLicense), applicable to } \\
\text { the online version of the article only. Usage and distribution for } \\
\text { commercial purposes requires written permission. }\end{array}$
\end{tabular}


Fig. 1. a Cross-section of the parasite with part of the organs in the pseudocoelom (HES, $\times 20)$. b Part of the cross-section showing longitudinal ridges on the outer surface of the cuticle and the inner muscle layer (HES, $\times 100)$.
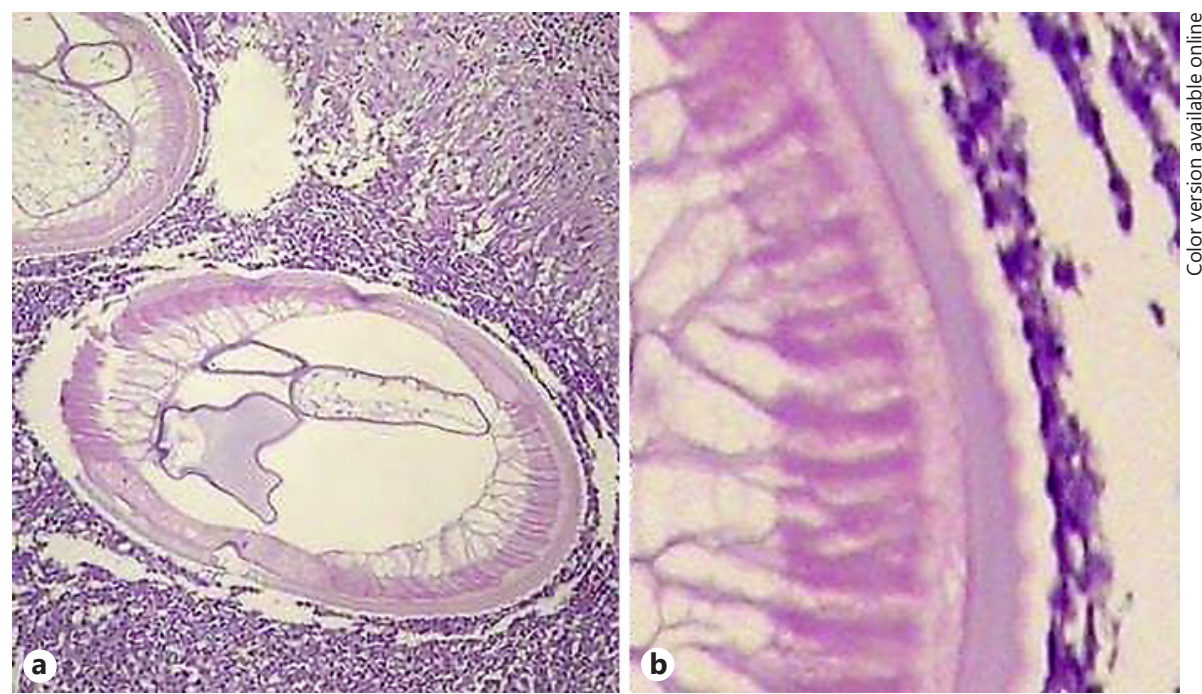

ported. A recent retrospective study of human dirofilariasis in Bulgaria for the period 1973-2011 described 47 recorded cases [4]. The youngest patient in the study was a 19-year-old male. Subcutaneous and ocular localizations were observed and only two cases with involvement of the male reproductive system were described $[4,5]$.

\section{Case Report}

An 11-year-old boy was admitted to the Clinic of Pediatric Urology for elective surgery of epididymal cyst on the left side. The cyst was painless and had been noticed by the parents a month ago. The child had no subjective complaints and felt well overall. Laboratory tests of blood and urine were unremarkable. Upon ultrasound examination of the left testicle, epididymal cyst with a size of 14/11 mm was visualized without any other pathological findings. The patient was offered surgical removal of the cyst. After removal, the cyst was sent for histological examination.

Microscopic examination of the histological slides revealed cross-sections of a nematode belonging to Dirofilaria spp. The cuticle was about $10 \mu \mathrm{m}$ thick with longitudinal ridges on the outer surface, which allowed us to differentiate the parasite morphologically as $D$. repens. In the pseudocoelom, parts of the alimentary and reproductive systems were observed (Fig. 1).

Anthelmintic therapy was not considered to be necessary in this case, and the patient was discharged the day after the surgery. At the 6-month follow-up, the child had fully recovered.

\section{Discussion}

Human dirofilariasis of the male reproductive system is rare, with about 20 cases reported in Europe, with localization of the parasite most often in the testicles, epididy- mis, and the spermatic cord [6]. Most authors assume that the frequency of such localization of the parasite is between 2 and $4 \%$ worldwide [7]. The clinical features of human dirofilariasis are not specific. Since the resulting infectious nodule in the male genitalia is frequently indistinguishable clinically from a malignant neoplasm, when systemic signs are absent and urine analysis is negative, the nodule is usually removed surgically $[6,8]$.

Until now, only one case of localization in the epididymis of a 31-year-old man was reported in Bulgaria [5]. Regardless of the localization, in our country this is the first reported case of a child affected by dirofilariasis. Worldwide cases of infected children are extremely rarely reported, with the exception of Russia and Sri Lanka [3, 9].

In Europe, dirofilariasis is a neglected infection, usually with or without minor clinical manifestations. The geographical distribution of human dirofilariasis coincides with that of the infected dogs. Not long ago, it was endemic mostly for the Mediterranean region and the eastern parts of the European continent, but now its geographic endemicity in Europe has increased [10]. There are also cases of people living outside endemic areas who were diagnosed with the disease after travelling to such places.

\section{Conclusion}

An important feature of the disease is that it is often erroneously diagnosed as malignancy that, in addition to the emotional stress, can lead to unnecessary and unpro- 
ductive diagnostic and therapeutic procedures. Although human dirofilariasis is not considered as a threat to the public health system, we believe that all clinicians and pathologists should be informed about it as it could help alleviate difficulties in its diagnosis.

\section{Disclosure Statement}

The authors report no conflict of interests.

\section{References}

1 Genchi C, Rinaldi L, Mortarino M, Genchi M, Cringoli G. Climate and Dirofilaria infection in Europe. Vet Parasitol. 2009 Aug;163(4): 286-92.

2 Genchi C, Kramer L. Subcutaneous dirofilariosis (Dirofilaria repens): an infection spreading throughout the old world. Parasit Vectors. 2017 Nov;10(S2 Suppl 2):517.

3 Morozov EN, Supriaga VG, Rakova VM, Morozova LF, Zhukova LA. [Human dirofilariasis: clinical and diagnostic signs and diagnostic methods]. Med Parazitol (Mosk). 2014 Apr-Jun;2(2):13-7.
4 Harizanov RN, Jordanova DP, Bikov IS. Some aspects of the epidemiology, clinical manifestations, and diagnosis of human dirofilariasis caused by Dirofilaria repens. Parasitol Res. 2014 Apr;113(4):1571-9.

5 Kaftandjiev IT, Harizanov RN. Rare case of epididymal dirofilariasis. QJM. 2016 May; 109(5):351-2.

6 Leccia N, Patouraux S, Carpentier X, Boissy C, Del Giudice P, Parks S, et al. Pseudo-tumor of the scrotum, a rare clinical presentation of dirofilariasis: a report of two autochtonous cases due to Dirofilaria repens. Pathog Glob Health. 2012 Oct;106(6):370-2.

7 Muro A, Genchi C, Cordero M, Simón F. Human dirofilariasis in the European Union. Parasitol Today. 1999 Sep;15(9):386-9.
8 Grover VK, Adib SM, Joseph L, Nur AM. The Etiology of Acute Scrotal Swelling on Surgical Exploration among Children and Adolescents in Jahra. Med Princ Pract. 1998;7(3): 192-7.

9 Dissanaike AS, Abeyewickreme W, Wijesundera MD, Weerasooriya MV, Ismail MM. Human dirofilariasis caused by Dirofilaria (Nochtiella) repens in Sri Lanka. Parassitologia. 1997 Dec;39(4):375-82.

10 Tomazatos A, Cadar D, Török E, Maranda I, Horváth C, Keresztes L, et al. Circulation of Dirofilaria immitis and Dirofilaria repens in the Danube Delta Biosphere Reserve, Romania. Parasit Vectors. 2018 Jul;11(1):392. 